

\title{
Análise das condições sociofamiliares de crianças em acolhimento institucional: Comparando dois momentos
}

\author{
Analysis of social-familiar conditions of children in shelter institutions: Comparing two moments
}

\author{
Lilia lêda Chaves Cavalcante ${ }^{[a]}$, Cristina Ribeiro de Araújo $0^{[b]}$, \\ Érica Luana Carneiro Góes ${ }^{[c]}$, Celina Maria Colino Magalhães ${ }^{[d]}$
}

\footnotetext{
${ }^{\text {[a] }}$ Doutora em Teoria e Pesquisa do Comportamento, professora da Universidade Federal do Pará, Belém, PA - Brasil, e-mail: liliaccavalcante@gmail.com

${ }^{[b]}$ Graduada em Serviço Social pela Universidade Federal do Pará, Belém, PA - Brasil, e-mail: djanecris@yahoo.com.br

${ }^{[c]}$ Graduada em Serviço Social pela Universidade Federal do Pará, Belém, PA - Brasil, e-mail: erica. goes17@gmail.com

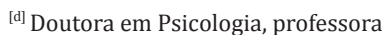
da Universidade Federal do Pará, Bolsista de Produtividade CNPq, Belém, PA - Brasil, e-mail: celinaufpa@gmail.com
}

Recebido: 21/07/2012 Received: 07/21/2012

Aprovado: 06/11/2012 Approved: 11/06/2012

\begin{abstract}
Resumo
Conhecer quais as condições contextuais nas quais o desenvolvimento infantil ocorre no Brasil é um importante desafio para pesquisas interdisciplinares atuais que procuram subsidiar políticas públicas. Isso significa conferir especial atenção a investigações que objetivam compreender as condições ecológicas nas quais as crianças estão submetidas em diferentes regiões do país. Este artigo pretende discutir as condições sociofamiliares de crianças que viviam em uma instituição de acolhimento infantil na região metropolitana de Belém, Pará, tomando como referência dados registrados em seus prontuários nos anos de 2004 (n=287) e 2009 (n=249). Para tanto, o estudo focalizou variáveis referentes à situação socioeconômica da família e sociojurídica da criança, em um intervalo de cinco anos. A análise comparativa dos resultados demonstra que os sinais da pobreza presentes no contexto pesquisado são mais graves do que os encontrados na população infantil geral, reforçando o argumento de que é necessário conhecer a extensão de seus efeitos sobre o desenvolvimento humano, sobretudo no caso de crianças na primeira infância expostas a condições ecológicas que tipicamente caracterizam as instituições de acolhimento.
\end{abstract}

Palavras-chave: Criança abandonada. Família. Lar. Desenho.

Abstract

To know about the background conditions in which child development occurs in Brazil is a major challenge for current interdisciplinary research that aim to support public policies This means paying special attention to investigations that aim to understand the ecological conditions in which children are subjected in different regions of the country. This article intends to discuss the social-familial conditions of children living in a child care institution in the metropolitan region of Belém, Pará, with reference to data in their records for the years $2004(n=287)$ and $2009(n=$ 249). Thus, the study focused on variables related to the socioeconomic status of the family and the social-legal condition of the child at an interval of five years. The comparative analysis of the results shows that the signs of poverty present in the studied context are more severe than those found in the general child population, supporting the argument that it is necessary to know the extent of their effects on human development, especially for early childhood children exposed to ecological conditions that typically characterize shelter institutions.

Keywords: Child Development. Poverty. User Embracement

Psicol. Argum. 2014 jan./mar., 32(76), 79-92 


\section{Introdução}

Existem evidências de que a condição das famílias de crianças de zero a três anos de idade seja um fator que tem profundas implicações para a formulação de políticas públicas de atenção ao desenvolvimento na primeira infância, particularmente quando destinadas à proteção social daqueles segmentos mais vulneráveis à pobreza, à doença e à violência. A primeira e mais importante destas evidências está sustentada em pesquisas que consideraram que investigar as características de tais famílias significa conhecer as condições em que estão sendo satisfeitas as necessidades da criança em seus primeiros anos de vida (Brazelton \& Greenspan, 2002). Por sua evidente importância para o desenvolvimento infantil, torna-se fundamental conhecer e monitorar a evolução das condições sociofamiliares nos anos iniciais. Neles, nota-se que a plasticidade cerebral - a capacidade do cérebro de se modificar em resposta a estímulos ambientais, ora pela criação e fortalecimento das conexões neurais, ora pelo enfraquecimento ou eliminação de outras ocorre com toda a sua capacidade (Bear, Connors \& Paradiso, 2008).

0 desenvolvimento do cérebro acontece em períodos considerados sensíveis pelos neurocientistas, porque sua atividade estaria especialmente concentrada na tarefa de formar estruturas e funções específicas que serão importantes para a toda a vida (Santos-Monteiro, Guedes, Castro \& Cabral Filho, 2002). Estes períodos devem ser reconhecidos como oportunidade para se incentivar o desenvolvimento da criança, embora nem sempre as políticas públicas de atenção à primeira infância consigam reconhecer e valorizar as particularidades da aprendizagem nesse momento (Barker \& Rizzini, 2002).

As experiências acumuladas durante esses períodos de maior sensibilidade arquitetam a estrutura física do cérebro da criança, porque nessas condições este órgão seria particularmente maleável e receptivo às pressões do meio externo e social. No entanto, deve-se considerar que essa plasticidade permite à criança dar respostas consequentes às pressões do meio que podem conduzir a um desenvolvimento tão pleno e saudável quanto possível, assim como o ajustamento do cérebro infantil aos recursos disponíveis em um ambiente sociofamiliar pobre em estímulos sensoriais e afetivos (Andrade et al. 2005; Ferreira \& Marturano, 2002; Gallo \& Williams, 2005). Em resumo, pode-se afirmar que as experiências da primeira infância têm um impacto duradouro sobre o cérebro do bebê e disso decorre seu desenvolvimento.

Atualmente, está mais claro que atividades positivas que promovem o desenvolvimento saudável têm consequências benéficas para a vida posterior (Halpern \& Figueiras, 2004; O'Donnell \& Porto, 2007; Poletto, Wagner \& Koller, 2004). Por outro lado, estudos mostram que as experiências que afetam ou levam ao desenvolvimento atípico da criança ou aquém do socialmente esperado estão associadas à qualidade e à quantidade do desenvolvimento cerebral nessa fase inicial em condições adversas (Vegas \& Santibáñez, 2010). Do mesmo modo, estudiosos do tema apontam que muito pode ser feito para se superar, entre outras situações adversas que levam à vulnerabilidade da família, os efeitos prejudiciais das desvantagens socioeconômicas para a criança (Aber, Bennett, Conley, Johnson \& Li, 1997; Brancalhone, Fogo \& Williams, 2004; Calamante, 2007; Habigzang, Koller, Azevedo, \& Machado, 2005; Paiva, Lima, Lima \& Eickmann, 2010; Rede Nacional Primeira Infância, 2010; Silva, Nunes, Betti \& Rios, 2008; Santos-Monteiro et al., 2002; Wolff \& Fesseha, 1999). O caminho está no compromisso de propiciar à criança experiências positivas capazes de promover o desenvolvimento do cérebro nos primeiros anos de vida, que encorajem as interações sociais entre a criança e seu ambiente imediato e que combatam os efeitos negativos da estimulação deficiente e cuidados negligentes nessa fase da vida.

Uma forma interessante de se predizer os fatores de risco e proteção à infância pode ter início com a adoção de uma perspectiva ecológica na pesquisa do desenvolvimento humano, como propôs Bronfenbrenner (1996). Este modelo teórico permite investigar mais amplamente os efeitos da pobreza e a melhor forma de preveni-los e revertê-los em contextos específicos, pensando este fenômeno de forma complexa e multideterminada (Barros, Carvalho \& Franco, 2006; Colombo, 2007).

Nesse sentido, pesquisas mostram que a renda das famílias desempenha um papel importante nas condições colocadas à aquisição de habilidades e competências socialmente valorizadas na vida adulta (Halpern, Barros, Horta \& Victora, 1996; Paiva et al., 2010; Silva et al., 2008). Por 
exemplo, crianças que vivem na companhia de cuidadores que enfrentam dificuldades econômicas estão mais expostas a deficiências nutricionais que levam ao retardo do crescimento e à desnutrição grave, favorecendo doenças e a morbidade na infância (Díaz, 2007; Dimenstein, Simplício, Ribeiro \& Melo, 2003; Fisberg, Marchioni \& Cardoso, 2004).

Assim, compreender e distinguir as implicações da renda familiar sobre os resultados do desenvolvimento da criança constitui um importante foco de interesse para pesquisadores da área de Psicologia e afins. Estudos recentes têm explorado os efeitos da renda familiar entre crianças consideradas em situação de vulnerabilidade social, particularmente as que foram encaminhadas para instituições de acolhimento e afastadas do convívio com os pais por razões associadas à privação precoce e/ ou pobreza extrema (Roy \& Rutter, 2006; Siqueira \& Dell'Aglio, 2006). Em geral, crianças que vivem nessas condições ecológicas podem não conseguir alcançar seu potencial pleno, dificultando seu desenvolvimento físico, cognitivo e socioemocional (Beckett et al., 2006; Roy, Rutter \& Pickles, 2000). Este quadro provoca preocupação porque é os resultados do desenvolvimento da primeira infância têm implicações ao longo da vida, afetando a produtividade e a capacidade da pessoa e sua renda futura, sua saúde laboral, longevidade e desenvolvimento do cérebro.

A literatura mostra que crianças institucionalizadas são quase que sinônimo de pobreza ou vulnerabilidade social (Bernal, 2004; Carvalho, 2002). Isso porque, em geral, estas são crianças oriundas de famílias com renda, moradia e escolaridade precárias, podendo ter sido expostas precoce e prolongadamente a vários tipos de privações e maus-tratos (Cavalcante, 2008; Cavalcante, Magalhães \& Costa 2012; Instituto de Pesquisa Econômica Aplicada [IPEA], 2004; Lewandowski, De Antoni, Koller \& Piccinini, 2002; Habigzang et al., 2005; Morais, Leitão, Koller \& Campos, 2004; Serrano, 2008; Sigal, Perry, Rossignol, \& Ouimet, 2003). Esses trabalhos indicam que a combinação explosiva entre pobreza, violência doméstica e consumo abusivo do álcool e outras drogas pelos pais são fatores que, quando associados, definem a condição da família como multiproblemática (Vegas \& Santibáñez, 2010). Estes e outros indicadores de vulnerabilidade social traduzem o nível de deterioração das condições gerais de vida da população infantil, o que pode criar situações propícias ao descumprimento da principal função parental: assegurar proteção à criança contra qualquer forma de abandono e violência.

Neste sentido, apresentamos dados referentes ao perfil sociodemográfico dos pais de crianças que estiveram sob a guarda de uma instituição de acolhimento em dois períodos diferentes: 2004 e 2009. Far-se-á considerações sobre constâncias e/ou alterações nos indicadores pesquisados nos dois momentos temporais, procurando apontar quais as principais mudanças observadas desde o primeiro levantamento realizado na instituição cinco anos atrás.

\section{Método}

Informantes

Uma equipe formada por cinco profissionais, todos eles funcionários da instituição de acolhimento infantil há pelo menos dois anos - sendo duas assistentes sociais, uma psicóloga, uma pedagoga e uma enfermeira -, forneceu informações relativas ao total de crianças encaminhadas e atendidas em uma instituição de acolhimento infantil $(n=287)$ entre os anos de 2004 e 2005. Cinco anos depois, uma equipe técnica composta por quatro assistentes sociais, duas psicólogas, uma pedagoga, uma enfermeira e sete técnicas de enfermagem, disponibilizou informações relativas às crianças atendidas no ano de 2009 ( $\mathrm{n}=249)$. Todas elas foram atendidas na mesma instituição da primeira fase da pesquisa.

\section{Ambiente}

A instituição pesquisada é considerada o maior abrigo infantil do Estado do Pará e está situada na região metropolitana de Belém. Desde sua fundação, em 1993, a instituição é responsável pelo acolhimento de crianças na faixa etária de zero a seis anos em situação de risco social e pessoal, conforme define o Estatuto da Criança e do Adolescente, promulgado em 1990. A média de atendimento por mês é de aproximadamente 60 crianças, embora já tenha acolhido até 90 crianças pouco antes do período estudado.

Psicol. Argum. 2014 jan./mar., 32(76), 79-92 
Instrumento e materiais

Para a coleta dos dados foi utilizado o instrumento elaborado por Cavalcante (2008), com base em um estudo anterior de Weber e Kossobudzki (1996) sobre a condição psicossocial de crianças que viviam em abrigos e instituições similares. Nesta versão, foram suprimidas, alteradas ou incluídas novas perguntas, adequando o instrumento às particularidades da população infantil alvo da pesquisa.

$\mathrm{O}$ instrumento foi composto majoritariamente por perguntas estruturadas e com múltiplas alternativas de resposta, organizadas em torno dos seguintes eixos: identificação pessoal (10 itens), estrutura familiar (19 itens), histórico de institucionalização (30 itens), situação sociojurídica atual (19 itens) e saúde da criança (16 itens).

A consulta foi feita diretamente em fontes documentais, assim como por meio de entrevista semiestruturada com profissionais dispostos a complementar as informações coletadas sobre o processo de acolhimento institucional das crianças. Nesta fase da pesquisa, a consulta foi realizada a partir do exame dos seguintes documentos: Estudo Social (dados sobre a composição familiar, condições de moradia, perfil dos pais e/ou responsáveis), Declaração de Nascido Vivo (informações sobre a gestação, a parturiente, o parto, as características do recém-nascido), Prontuário Médico (anotações sobre condição geral de saúde ao ingresso no abrigo e ao longo da sua permanência) e Termo de Encaminhamento do Conselho Tutelar (relatos sobre a condição sociojurídica da criança).

Procedimento

0 estudo teve início com o pedido de autorização ao titular da Vara da Infância e Juventude do Tribunal de Justiça do Estado do Pará para a realização da pesquisa nas dependências da instituição proposta, permitindo o acesso dos pesquisadores à equipe técnica e aos documentos que registravam aspectos da história de vida e condição sociojurídica do total de crianças acolhidas no período considerado. A proposta de estudo foi submetida à apreciação do Comitê de Ética para Pesquisas com Seres Humanos do Núcleo de Medicina Tropical da Universidade Federal do Pará, tendo sido aprovada sua realização sem qualquer restrição ou recomendação especial.

Foi feita uma reunião com a equipe técnica para apresentar os objetivos e o método da pesquisa, além de motivar a colaboração de todos com as informações e os esclarecimentos necessários. Após essa reunião, foi realizada a seleção do material a ser utilizado pela pesquisa a partir de critérios como legitimidade e confiabilidade (priorizaram-se documentos oficiais e rejeitaram-se certidões com rasuras ou ilegíveis e anotações informais). Esse procedimento assegurou a formação de uma base de dados com boa margem de fidedignidade, na medida em que a possibilidade de comparar registros disponíveis em mais de uma fonte permitiu aos pesquisadores identificar lacunas e contornar eventuais dificuldades. Entre os problemas esperados estão a dispersão de dados e a imprecisão de informações contidas em relatórios elaborados por técnicos da instituição.

Na proporção em que os documentos eram examinados, as informações foram registradas em um formulário elaborado especificamente para esse fim. Em seguida foi feita entrevista com membros da equipe técnica da instituição no sentido de complementar e/ou validar as informações obtidas em fontes documentais.

A definição das variáveis, categorias e unidades de análise utilizadas neste estudo orientou a transcrição e organização dos dados e, posteriormente, o tratamento estatístico desse material por meio de planilhas eletrônicas feitas no software Microsoft Excel. Ao final, o sistema de apresentação dos resultados obtidos foi estruturado em torno das seguintes unidades de análise: idade e sexo das crianças, local de nascimento, pessoa de referência na família, paternidade reconhecida no Registro Civil e dados sobre os pais e/ou responsável familiar, como idade, escolaridade, ocupação, renda e condições de moradia.

\section{Resultados}

Os dados apresentados nesta seção de resultados descrevem as condições sociofamiliares de crianças em situação de risco pessoal e social encaminhadas a uma instituição de acolhimento infantil nos anos de 2004 (n=287) e 2009 ( $n=249)$. A análise comparativa dos resultados obtidos nos dois períodos de tempo permitiu apontar semelhanças e diferenças no perfil das famílias pesquisadas, nas condições de moradia apresentadas pelos pais e nos motivos que justificaram o acolhimento infantil como medida jurídica de proteção especial, conforme prevê o ECA. 
Entre os principais resultados, os dados revelaram que em $40,41 \%$ dos casos referentes ao ano de 2004 as crianças foram encaminhadas à instituição de acolhimento por um conjunto de fatores relacionados ao contexto de privação material e emocional que caracterizava seu meio sociofamiliar. A maioria das crianças pesquisadas foi encaminhada à instituição por mais de um motivo (59,59\%). Foram identificados vários motivos (ora mencionados de forma independente, ora associados a outros) que estão por trás da decisão judicial de manter essas crianças sob a guarda e os cuidados diários da instituição em regime de acolhimento provisório. No ano de 2009, os dados sugerem que os motivos apontados para apoiar a decisão pelo acolhimento institucional não foram diferentes do período anterior, como mostra a Tabela 1.

Os resultados válidos para 2004 e 2009 demonstraram que a negligência familiar - seja como motivo único para o acolhimento da criança $(35,89 \%$ e $6,82 \%)$, seja quando apareceu relacionada a outras vicissitudes experienciadas pela família $(63,06 \%$ e $51 \%$ ) - foi uma categoria que liderou o ranking dos fatores que teriam justificado seu encaminhamento para a instituição. A Tabela 1 mostra que outros motivos foram mencionados de forma recorrente nos documentos referentes aos atendimentos realizados pela instituição nos dois momentos: 0 abandono familiar (24,43\% e 45,38\%), a dependência do álcool e outras drogas por parte dos pais e/ou responsáveis $(14,63 \%$ e 26,1\%) e a violência física e sexual que atinge a criança, sobretudo no ambiente doméstico $(14,98 \%$ e $11,24 \%)$.

Na primeira amostra, em $24,1 \%$ dos casos, o motivo para o acolhimento da criança esteve associado à carência de recursos materiais dos pais e/ou responsáveis, o que em geral diz muito sobre a condição de pobreza e vulnerabilidade social da família como um todo. Já na amostra mais recente, este traço da condição sociofamiliar das crianças, apesar de supostamente comum nessa população infantil, foi citado como motivo para sua longa permanência na instituição em 16,86\% do total de casos examinados.

A presumida condição de pobreza e vulnerabilidade de crianças em situação de acolhimento institucional, neste estudo, parece ter sido confirmada em razão das características predominantes no perfil sociodemográfico de seu responsável familiar, segundo revelam dados apurados nos dois estudos feitos na instituição, tais como idade, escolaridade, ocupação e renda. Especificamente, na análise da primeira variável, verificou-se que, em 2004 e 2009, a maioria das crianças tinha pai $(16,38 \%$ e $15,26 \%)$ e/ou mãe $(53,66 \%$ e 58,24\%) com idade entre 19 e 30 anos. É curioso notar que no primeiro levantamento foi maior o percentual de crianças cujo pai

Tabela 1 - Percentual de crianças de acordo com a justificativa mencionada para 0 acolhimento institucional, nos anos de 2004 e 2009

\begin{tabular}{lcccc}
\hline \multirow{2}{*}{ Justificativa } & \multicolumn{2}{c}{$\mathbf{2 0 0 4}(\mathbf{n = 2 8 7})$} & \multicolumn{2}{c}{$\mathbf{2 0 0 9}(\mathbf{n = 2 4 9 )}$} \\
\cline { 2 - 5 } & $\begin{array}{c}\text { Motivo } \\
\text { Único }\end{array}$ & $\begin{array}{c}\text { Motivo } \\
\text { Associado }\end{array}$ & $\begin{array}{c}\text { Motivo } \\
\text { Único }\end{array}$ & $\begin{array}{c}\text { Motivo } \\
\text { Associado }\end{array}$ \\
\hline Abandono & 9,76 & 24,43 & 12,44 & 45,38 \\
Deficiência física ou mental dos pais & 2,79 & 4,18 & 0 & 0 \\
Dependência de álcool e outras drogas dos pais & 0,69 & 14,63 & 12,04 & 26,1 \\
Doença física e/ou mental dos pais & 0,35 & 1,39 & 0,4 & 5,22 \\
Impedimento judicial & 1,74 & 6,62 & 0 & 0 \\
Negligência familiar & 35,89 & 63,06 & 6,82 & 51 \\
Pobreza e vulnerabilidade social dos pais & 3,49 & 6,69 & 1,2 & 16,86 \\
Situação de rua & 0,35 & 1,74 & 0,4 & 1,6 \\
Violência física & 2,79 & 13,24 & 1,2 & 8,03 \\
Violência sexual & 0,35 & 1,74 & 1,2 & 3,21 \\
Outros motivos & 1,39 & 5,22 & 6,42 & 23,69 \\
\hline
\end{tabular}

Fonte: As autoras.

Psicol. Argum. 2014 jan./mar., 32(76), 79-92 
Tabela 2 - Percentual de crianças em situação de acolhimento institucional de acordo com as características sociodemográficas dos pais, nos anos de 2004 e 2009

\begin{tabular}{|c|c|c|c|c|}
\hline \multirow{2}{*}{ Categorias } & \multicolumn{2}{|c|}{$2004(n=287)$} & \multicolumn{2}{|c|}{$2009(n=249)$} \\
\hline & Mãe & Pai & Mãe & Pai \\
\hline \multicolumn{5}{|l|}{ Idade } \\
\hline$<16$ anos & 0,69 & 0 & 1,61 & 0 \\
\hline 17-18 anos & 6,97 & 1,39 & 2,01 & 0,4 \\
\hline 19-30 anos & 53,66 & 16,38 & 58,24 & 15,26 \\
\hline $31-40$ anos & 10,81 & 8,02 & 16,46 & 10,45 \\
\hline $41-50$ anos & 0,69 & 6,62 & 3,22 & 4,81 \\
\hline $51-60$ anos & 0,35 & 1,74 & 0 & 2,01 \\
\hline$>60$ anos & 0 & 1,74 & 0 & 0 \\
\hline Sem referência materna/paterna & 1,39 & 31,70 & 11,24 & 56,62 \\
\hline Sem informação & 25,44 & 32,41 & 7,22 & 10,45 \\
\hline \multicolumn{5}{|l|}{ Escolaridade } \\
\hline Analfabeto(a) & 2,78 & 0 & 6,43 & 2,01 \\
\hline Ensino fundamental incompleto & 11,51 & 4,19 & 51,81 & 12,86 \\
\hline Ensino fundamental completo & 2,09 & 2,44 & 1,6 & 0,4 \\
\hline Ensino médio incompleto & 1,39 & 0,35 & 6,03 & 0,4 \\
\hline Ensino médio completo & 0,35 & 0 & 0,81 & 6,03 \\
\hline Ensino superior incompleto & 1,39 & - & 0 & 0 \\
\hline Sem referência materna/paterna & 1,39 & 31,70 & 11,24 & 56,62 \\
\hline Sem informação & 79,10 & 61,32 & 22,08 & 21,68 \\
\hline \multicolumn{5}{|l|}{ Ocupação } \\
\hline Empregado(a) & 23,35 & 19,86 & 8,84 & 9,24 \\
\hline Desempregado(a) & 19,17 & 2,43 & 35,34 & 1,6 \\
\hline Trabalhador informal & 8,01 & 10,81 & 14,46 & 18,48 \\
\hline Aposentado & 0 & 1,74 & 0 & 0 \\
\hline Outros & 0 & 0,35 & 0 & 0 \\
\hline Sem referência materna/paterna & 1,39 & 31,70 & 11,24 & 56,62 \\
\hline Sem informação & 48,08 & 33,11 & 30,12 & 14,06 \\
\hline \multicolumn{5}{|l|}{ Renda } \\
\hline < 1 salário mínimo & 11,84 & 3,13 & 16,06 & 4,42 \\
\hline Exatamente 1 salário mínimo & 1,75 & 2,09 & 6,03 & 10,85 \\
\hline > 1 salário mínimo & 2,79 & 8,37 & 0,4 & 6,03 \\
\hline Sem referência materna/paterna & 1,39 & 31,70 & 11,24 & 56,62 \\
\hline Sem informação & 82,23 & 54,71 & 35,75 & 19,68 \\
\hline Sem renda & 0 & 0 & 30,52 & 2,4 \\
\hline
\end{tabular}

Fonte: As autoras.

tinha idade superior a 60 anos $(1,74 \%)$ do que os que se encontravam na adolescência $(1,39 \%)$, mas o mesmo não foi verificado na consulta seguinte. Em contrapartida, como ilustra a Tabela 2, em 2004 foi possível registrar um percentual de crianças que eram filhos de mães com até 18 anos completos
(7,66\%), embora situação semelhante não tenha sido observada em 2009.

Com relação à escolaridade do pai, a Tabela 2 indica que, em que pese o expressivo número de casos levantados que não dispunham de informações precisas sobre esta e outras variáveis estudadas 
(61,32\% e $21,68 \%)$, ou ainda, subtraindo-se as crianças que efetivamente não possuíam referência paterna $(31,71 \%$ e $56,62 \%)$, os dados sugerem a existência de um percentual significativo de pais que contavam com poucos anos de estudo. Em 2004 $(0,4 \%)$ e 2009 (2,43\%), em vários casos o pai da criança não havia concluído sequer o ensino fundamental e abandonara a escola já nas séries iniciais. Quanto à escolaridade da mãe, cabe destacar que, no primeiro levantamento, em $79,45 \%$ dos casos esta informação não estava disponível para consulta, porém, cinco anos depois, este percentual sofreu redução significativa $(22,08 \%)$. Apesar da evidente omissão de dados sobre a escolaridade dos pais, fato que, sem dúvida, marcou a primeira e a segunda coleta feita nos prontuários da instituição, encontraram-se muitos casos em que a mãe fora reconhecida como analfabeta $(2,78 \%)$, ao contrário do pai, cuja categoria não apresentou nenhum caso. Em contrapartida, constatou-se que houve um aumento no número de mães que cursavam ou tinham concluído as etapas do ensino médio (de $2 \%$ para $8,5 \%$ ).

Em que pese o elevado número de casos nos quais a documentação consultada não informava com precisão a ocupação do pai $(33,11 \%$ e $14,06 \%)$ e da mãe (48,08\% e 30,12\%), os números indicaram que $8,01 \%$, em $2004,14,46 \%$, em 2009 , diziam respeito a crianças apontadas como filhos de mulheres jovens ou adultas que desenvolviam qualquer atividade ou trabalho no âmbito do mercado informal, especialmente na área de serviços (empregadas domésticas, faxineiras, vendedoras de cosméticos, manicures, costureiras, ambulantes, prostitutas, entre outras). Com relação aos pais, uma situação semelhante foi encontrada a partir do levantamento dessas informações nos dois períodos $(10,81 \%$ e $18,48 \%$ ). As crianças cujos pais estavam envolvidos em atividades ocupacionais situadas no mercado informal (serviços gerais, construção civil e comércio), ou nos casos em que os mesmos não estavam vinculados a qualquer forma de trabalho regular e/ ou com vínculo empregatício no período de duração da pesquisa, foram registradas em ambos os levantamentos realizados na instituição.

Entre as crianças acolhidas pela instituição no ano de $2004,3,13 \%$ dos pais e $11,84 \%$ das mães apresentavam renda mensal inferior a $R \$ 260,00$, valor que correspondia ao salário mínimo vigente à época da pesquisa. No ano de 2009, 4,42\% dos pais e $16,06 \%$ das mães declararam possuir renda inferior a um salário mínimo vigente na ocasião, isto é, $\mathrm{R} \$ 465,00$.

Com relação às características dos domicílios onde as crianças viviam com seus pais e/ou responsáveis, considerou-se para análise as seguintes variáveis: a situação do imóvel, o número de cômodos, o uso de iluminação elétrica e a presença de redes de esgotamento sanitário. Como mostra a Tabela 3, entre 2004 e 2009 cresceu ligeiramente o número de crianças provenientes de famílias que declararam possuir imóvel próprio $(59,75 \%$ e $60,87 \%)$ e diminuiu o percentual das que residiam em casa ou quarto alugado $(26,42 \%$ e $18,84 \%)$, assim como a proporção daquelas que moravam com os pais em casas de madeira $(54,61 \%$ para $46,23 \%)$.

Tabela 3 - Percentual de crianças de acordo com características que definem a condição de moradia da família, nos anos de 2004 e 2009

\begin{tabular}{|c|c|c|}
\hline Categorias & $\begin{array}{c}2004 \\
(n=287)\end{array}$ & $\begin{array}{c}2009 \\
(n=249)\end{array}$ \\
\hline \multicolumn{3}{|l|}{ Situação do Imóvel } \\
\hline Próprio & 59,75 & 60,87 \\
\hline Alugado & 26,42 & 18,84 \\
\hline Cedido & 13,21 & 17,39 \\
\hline Outros & 0,62 & 2,90 \\
\hline \multicolumn{3}{|l|}{ Tipo de Construção } \\
\hline Madeira & 54,60 & 46,23 \\
\hline Alvenaria & 45,40 & 52,76 \\
\hline Barro & 0,00 & 1,01 \\
\hline \multicolumn{3}{|l|}{ Número de Cômodos } \\
\hline Um cômodo & 39,09 & 34,57 \\
\hline Dois cômodos & 14,29 & 22,34 \\
\hline Três cômodos & 21,81 & 20,74 \\
\hline Quatro cômodos & 15,03 & 17,55 \\
\hline Cinco cômodos & 9,02 & 3,73 \\
\hline Seis ou mais cômodos & 0,76 & 1,07 \\
\hline \multicolumn{3}{|l|}{$\begin{array}{l}\text { Fornecimento de } \\
\text { Energia }\end{array}$} \\
\hline Sim & 99,04 & 98,84 \\
\hline Não & 0,96 & 1,16 \\
\hline \multicolumn{3}{|l|}{ Instalações Sanitárias } \\
\hline Sim & 76,47 & 88,81 \\
\hline Não & 23,53 & 11,19 \\
\hline
\end{tabular}

Psicol. Argum. 2014 jan./mar., 32(76), 79-92 
Nos anos de 2004 e 2009, os dados definiram o seguinte quadro: entre as crianças, prevaleceram as que moravam com os pais em unidades residenciais que contavam com apenas um cômodo $(39,09 \%$ e $34,57 \%$ ), sendo geralmente quartos construídos ou alugados em vilas populares e/ou na casa de membros da família extensa. Nas duas consultas realizadas na instituição, as informações disponíveis dão conta que quase $100 \%$ das famílias das crianças faziam uso de iluminação elétrica, ainda que por meio de instalações clandestinas, recurso bastante utilizado nas periferias das grandes cidades. No que se refere à presença de instalações sanitárias, em 76\% (2004) e 88,81\% (2009) dos casos analisados constatou-se que a família da criança possuía em seu domicílio equipamentos sanitários básicos (rede geral de esgotamento, fossa séptica etc.).

\section{Discussão}

Os resultados apresentados não deixam dúvida de que as situações de negligência familiar constituíram o motivo mais comumente associado à decisão de se proceder ao acolhimento institucional de criança em situação de vulnerabilidade social, considerando-se os dois períodos analisados. Assim, uma parte significativa dos casos examinados aponta para a existência de crianças que, entre outras situações consideradas de risco ao desenvolvimento nos anos iniciais, foram encontradas em local e horário impróprios à sua faixa etária, muitas vezes sozinhas, ou na companhia de outras crianças - irmãos, amigos e vizinhos. Da mesma forma, foram relatos casos de negligência familiar que denunciaram a realidade de crianças deixadas sozinhas em casa, que não contavam com a atenção e os cuidados de um adulto responsivo às suas demandas, apresentando condições precárias de nutrição, higiene e saúde. Estes dados são particularmente importantes para estudiosos da primeira infância, porque a literatura afirma que nascer e crescer em um meio sociofamiliar que apresenta um conjunto de fatores que levam à vulnerabilidade social da família e da criança (Barros et al., 2006; Fundo das Nações Unidas para a Infância [Unicef], 2005) afeta o desenvolvimento do cérebro e prejudica a formação de ligações neurais subjacentes às aquisições que são esperadas nos primeiros anos de vida (Aber et al., 1997).
Entre os casos examinados na instituição pesquisada, chama atenção o fato de que as crianças deram entrada na instituição em razão de atitudes de negligência por parte de seus cuidadores primários, mas os dados coletados sugerem tratar-se frequentemente de um ambiente familiar pouco capaz de atender às necessidades infantis decorrentes das tarefas do desenvolvimento nesse período de maior sensibilidade e exigências mais complexas (Andrade et al., 2005; Barros et al., 2006; Dimenstein et al., 2003; Ferreira \& Marturano, 2002; Gallo \& Williams, 2005; SantosMonteiro et al., 2002). Em geral, o ambiente familiar de crianças que se encontram nessa condição especial (negligenciadas em seus cuidados básicos, maltratadas ou abandonadas) tem sido considerado por pesquisadores atuais como empobrecido sob diferentes aspectos (material, emocional e moral), conforme mostram estudos presentes na literatura nacional (Bernal, 2004; Carvalho, 2002; Siqueira \& Dell'Aglio, 2006) e internacional (Beckett et al., 2006; Roy et al., 2000; Roy \& Rutter, 2006; Wolff \& Fesseha, 1999).

Além disso, resultados desta pesquisa guardam relação com os motivos apontados para o acolhimento institucional encontrados em estudos sobre a realidade dos abrigos e dos abrigados no Brasil (Cavalcante, 2008; IPEA, 2004; Morais et al., 2004; Serrano, 2008). No levantamento feito pelo IPEA (2004), em particular, fica claro que os motivos que justificam a institucionalização de crianças e adolescentes se relacionam principalmente à condição de pobreza e vulnerabilidade social das famílias brasileiras (trabalho, escolaridade, renda, moradia, acesso a serviços básicos historicamente têm a marca da precariedade), como explicam Cavalcante et al. (2012).

Outro motivo que costuma justificar o acolhimento institucional, segundo a literatura sobre o tema e dados apresentados neste estudo, seria o fato de que crianças que passam a viver em instituições assim o fazem porque sistematicamente foram vítimas de agressão física e abuso sexual por parte dos pais e/ou responsáveis (em 2004, 14,98\% das crianças estavam no abrigo por este motivo e outros a ele associados, enquanto em 2009 este percentual foi de 2,4\%). Estudos mostram que a ocorrência de diferentes formas de abuso e violência contra a criança aparece relacionada à existência de situações de crise enfrentadas por grupos familiares de diferentes classes sociais, mas, supostamente, em contextos marcados pela pobreza este tipo de comportamento parental tem encontrado solo fértil 
para sua manifestação (Brancalhone et al., 2004; Habigzang et al., 2005).

Adicionalmente, os resultados aqui relatados indicaram que, para $14,63 \%$ das crianças, a dependência química dos pais e/ou responsáveis foi registrada como o motivo que justificou o acolhimento da criança. No levantamento nacional feito pelo IPEA (2004), 11,3\% das crianças e dos adolescentes que viviam em abrigos no Brasil foram acolhidos por esse motivo específico. Na região Norte, este percentual era de $7,1 \%$.

Entre as situações de crise que funcionam como fatores de risco para o abuso infantil, segundo Habigzang et. al. (2005) e Lewandowski, et al. (2002), destacam-se o desemprego prolongado de qualquer um dos cônjuges (sinônimo de impotência, ócio, insegurança e instabilidade financeira), as separações conjugais (sem definição clara das responsabilidades devidas a partir de então aos filhos) e o uso abusivo do álcool e outras drogas por parte dos pais e/ou responsáveis.

É importante ressaltar, contudo, que muitas dessas crianças foram encaminhadas à instituição por um conjunto de motivos que expressavam diversas carências e vicissitudes de seu grupo familiar. Nessas condições contextuais, supõe-se que essas crianças são oriundas de famílias multiproblemáticas e encaminhadas para uma instituição socioassistencial encarregada de lhes assegurar proteção especial. Entretanto, admite-se que quando essas crianças não recebem o atendimento adequado às demandas da família como um todo, passam a ter mais chance de experimentar a completa apartação de seu meio de origem e a ruptura dos laços afetivos com seus pais e/ou parentes próximos.

Silva et al. (2008) consideram que variáveis que traçam um perfil da família devem ser consideradas sempre que se quer investigar a extensão dos efeitos que determinadas características têm sobre o desenvolvimento infantil. Nesse sentido, a idade, a escolaridade, a ocupação e a renda do pai e da mãe são exemplos de variáveis que impactam de forma diferenciada o que se considera como endereço social da criança (Belsky, 1995) e a ecologia de seu contexto de desenvolvimento (Bronfenbrenner, 1996), embora seja preciso notar que tais características têm seus efeitos melhor percebidos e potencializados quando são analisadas em termos sistêmicos.

Nos anos de 2004 e 2009, observou-se que, com relação à idade dos pais, os resultados contrariaram a ideia de que as crianças que vivem em instituições de abrigo são filhos de pais e/ou mães adolescentes, com precária rede de apoio social. Na verdade, em ambos os estudos, os dados mostraram que em sua maioria as crianças são filhos de pais e mães que têm entre 19 e 30 anos. A literatura discute que em qualquer idade a maternidade/paternidade deve ser compreendida como uma experiência complexa porque invoca uma multiplicidade de fatores intrínsecos à ecologia do cuidado parental: as características dos pais, das crianças e do ambiente onde estes subsistemas estão em interação. Entretanto, em condições de maior vulnerabilidade social, os resultados parecem indicar que, independentemente da idade, pais e mães podem falhar ou se ausentar no cumprimento de suas responsabilidades, porque a violência e o abandono são processos que resultam de fatores internos (hostilidade, rejeição e autoritarismo nas relações pessoais) e externos à família (vulnerabilidade social e econômica), como explicam Lewandowski et al. (2002), Brazelton e Greenspan (2002) e Habigzang et al., (2005).

A idade dos pais pode se constituir, portanto, em uma variável importante para a discussão, desde que esteja associada a outros indicadores, como o grau de escolaridade, o nível de autonomia financeira e a presença de rede social de apoio. Neste estudo, percebe-se que quase todas as crianças que compuseram as duas amostras da pesquisa têm mãe e/ou pai com ensino fundamental incompleto $(11,51 \%$ e $4,19 \%$, em 2004 , e $51,81 \%$ e $12,86 \%$, em 2009). Para Kappel (2007), características como esta podem ter impacto negativo não apenas sobre as condições sociofamiliares da criança nos primeiros anos de vida, mas igualmente sobre o cálculo do Índice de Desenvolvimento Infantil (IDI) de um município ou país. Esta preocupação também é partilhada em documentos divulgados pelo Unicef (2005). Em outros trabalhos, Fisberg et al. (2004) e O'Donnell \& Porto (2007) reconhecem a escolaridade dos pais e/ou cuidadores habituais como uma variável fundamental para pesquisas que objetivam contribuir com estratégias de redução do índice de mortalidade infantil, por exemplo, entre outras ações de promoção do desenvolvimento infantil.

Outra variável analisada diz respeito à ocupação dos pais e mostra que o número de crianças cujas mães se encontravam desempregadas $(19,17 \%$ e $35,34 \%$ ) continuou, passados cincos anos, superior ao dos pais $(2,43 \%$ e 1,6\%). É interessante ressaltar

Psicol. Argum. 2014 jan./mar., 32(76), 79-92 
que as taxas de desemprego referentes aos pais das crianças não seguem rigorosamente as estatísticas divulgadas pela Pesquisa Nacional por Amostra de Domicílios 2004. Na população pesquisada, foram encontrados percentuais mais altos de desemprego e vínculo com o mercado informal do que na população brasileira em sua totalidade. Segundo o IBGE (2006), 11,5\% dos brasileiros com dez ou mais anos de idade encontravam-se à época sem ocupação. No levantamento de 2004, o percentual de crianças cujas mães declararam-se desempregadas $(19,17 \%)$ foi maior do que o encontrado nas estatísticas nacionais $(14,4 \%)$, já a porcentagem de pais que estavam desempregados nesse mesmo período foi significativamente menor do que os números oficiais divulgados $(2,43 \%)$. Com relação à variável renda, dados apresentados pela PNAD 2004 deram conta de que, no Pará, 9,68\% das pessoas com idade igual ou superior a dez anos de idade possuíam rendimentos de trabalho que não ultrapassavam meio salário mínimo. Esses números estavam em sintonia com as estatísticas nacionais fornecidas no período $(9,2 \%)$. Entre as crianças acolhidas pela instituição nos dois períodos pesquisados, 3,13\% dos pais e $11,84 \%$ das mães apresentavam rendimentos de trabalho inferiores ao salário mínimo vigente no momento em que os levantamentos foram realizados.

Segundo Petetta (2007), em geral, os estudos sobre pobreza a tomam como sinônimo de escassez de recursos. Nesses termos, a insatisfação de aspectos essenciais do desenvolvimento da vida social marca a linha abaixo da qual estão situados os lugares e as pessoas em situação de pobreza absoluta. Isso significa que a inserção no setor informal do mercado de trabalho, o déficit habitacional e sanitário, o atraso escolar e o analfabetismo são exemplos de condicionantes que têm implicações importantes para o desenvolvimento biopsicossocial de crianças e famílias que vivem nessas condições (Paiva et. al., 2010; Poletto et al., 2004). Considera-se, assim, que os resultados desta pesquisa corroboram o argumento de que a condição socioeconômica das crianças em acolhimento institucional e de seus pais é igual ou mais grave que a situação da maioria dos brasileiros na mesma faixa de idade.

Segundo resultados da PNAD 2006, 39,1\% das famílias com crianças de 0 a 14 anos viviam com renda mensal de até meio salário mínimo vigente no ano de 2005. Na região Norte, esse percentual foi maior que a média nacional $(45,0 \%)$, assim como, em particular, no estado do Pará $(47,3 \%)$ e na região metropolitana de Belém (43,7\%). Pelos números apresentados, considera-se que, acompanhando uma tendência mundial, tal qual argumentam Petetta (2007) e Unicef $(2004,2005)$, a parcela mais jovem da população tende a ser mais afetada, o que têm implicações para o desenvolvimento futuro de indivíduos e sociedades (Halpern \& Figueiras, 2004).

Quando se focalizam os dados disponíveis acerca das condições de moradia nos dois períodos considerados pela pesquisa, constata-se que o quadro geral dessa população infantil apresenta alterações que podem indicar sua tendência de melhora, ainda que outros indicadores pudessem contribuir para elucidar a real situação das famílias nesse contexto específico (Calamante, 2007).

Pelo exposto, pode-se concluir que, com os avanços tecnológicos e científicos nas áreas de conhecimento e atenção ao desenvolvimento na primeira infância, investimentos múltiplos devem ser realizados de forma a assegurar que estes não signifiquem simplesmente a responsabilidade com seus cuidados físicos diários, mas também outras qualidades que devem ser agregadas a esse sistema: conjugar estabilidade emocional e riqueza de estímulos e meios do ambiente onde ela irá crescer durante os primeiros anos da infância, o que pode ser seriamente comprometido quando existe o risco social e a degradação da vida humana gerada pela pobreza, como analisam Colombo (2007) e Barker e Rizzini (2002). Em estudos sobre famílias de crianças em situação de vulnerabilidade social, acolhidas em instituições socioassistenciais ou não, as condições de moradia, a ocupação profissional, a escolaridade e a renda mensal dos pais ou outros cuidadores são variáveis importantes quando se objetiva proceder à identificação do endereço social (Belsky, 1995), porém, não podem ser tomadas como fatores suficientes para explicar de forma consistente a variabilidade da ecologia do desenvolvimento humano. As variáveis que constituem o endereço social não devem ser entendidas como o contexto de desenvolvimento em si, mas como processos proximais que podem ampliar a compreensão do papel do contexto nas trajetórias desenvolvimentais a partir do sistema onde as crianças estão inseridas, como discute Bronfenbrenner (1996). 


\section{Considerações finais}

Ao caracterizar as condições sociofamiliares de crianças atendidas em um espaço de acolhimento com base no perfil de seus pais e os motivos que justificaram a aplicação desta medida sociojurídica de proteção à infância, compreende-se a relevância de estudos que, como este, possibilitam apontar aspectos estruturantes deste contexto ecológico de desenvolvimento e retratam aspectos do modo de vida de uma parcela expressiva das famílias de crianças brasileiras nos primeiros anos de vida.

Os motivos que levam ao acolhimento institucional foram os mais variados, contudo, ao se relacionar estes dados com características que integram o perfil das famílias de crianças consideradas em situação excepcional, verificou-se que grande parte dos pais encontrava-se em situação de notória pobreza, assim como amplas parcelas da população que vive no país. Portanto, conhecer como essa condição de vulnerabilidade social se apresentou para essa população específica nos dois momentos citados é considerado parte do compromisso que devem ter os pesquisadores do desenvolvimento na primeira infância com a compreensão dos efeitos derivados das situações de privação que tipicamente caracterizam a pobreza.

Mesmo sabendo que a pobreza é expressão direta das relações sociais vigentes na sociedade, a compreensão deste fenômeno não pode estar restrita às privações materiais, ainda que as condições socioeconômicas sejam fatores determinantes no nível de acesso da criança às oportunidades que permitem um desenvolvimento saudável e rico em possibilidades humanas. Nascer e viver sob o signo da pobreza remete à atenção com as diferentes formas de privação e/ou limitações de ordem emocional, material ou social, que podem atingir gravemente a criança nesses períodos de maior sensibilidade em termos desenvolvimentais.

Os resultados destacaram que, na maioria dos casos analisados, havia indícios de que as crianças encaminhadas à instituição não recebiam os cuidados adequados no meio familiar. Evidenciaram a existência de situações frequentes de negligência e abandono por parte dos pais e/ou responsáveis. Todavia, os mesmos dados levam a pensar que a adoção de medidas de enfrentamento da pobreza pensadas em uma perspectiva ecológica - ou seja, envolvendo estruturas micro e macrossistêmicas - poderia reduzir significativamente o número de crianças que passam os anos da infância em instituições socioassistenciais, porque faltam ações de apoio aos pais na execução de suas funções parentais fundamentais, conforme discute a Rede Nacional Primeira Infância (2010).

Finalmente, é preciso destacar que qualquer medida no campo das políticas públicas centradas na promoção do desenvolvimento na primeira infância deve se apoiar em dados fidedignos e atualizados sobre a condição sociofamiliar das famílias de crianças em diferentes contextos ecológicos. Esta é a condição fundamental para que tais intervenções possam ser acompanhadas e avaliadas em seus efeitos para o desenvolvimento infantil. Afinal, investigar as características sociofamiliares de determinada população infantil deve ser um objetivo a ser perseguido pelos pesquisadores de forma sistemática na atualidade, pois apenas isto será suficiente para permitir a comparação de análises compondo uma série histórica, a projeção de resultados esperados para o futuro e o significado de aquisições e déficits em diferentes contextos ecológicos. Isto vale para a compreensão da realidade infantil na instituição pesquisada e para as crianças em geral que vivem no Brasil ou em outros países. Tal situação nos remete à tarefa de propor e acompanhar o planejamento e a atuação dos responsáveis pela gestão dessas informações, objetivando minimizar lacunas, imprecisões e vieses na leitura de quadros dessa realidade sociofamiliar.

\section{Referências}

Aber, J. L., Bennett, N. G., Conley, D. C., Johnson, R. W., \& Li, J. (1997). The effects of poverty on child health and development. Annual Review Public Health, 18, 463-483.

Andrade, S. A., Santos, D. N., Bastos, A. C., Pedromônico, M. R. M., Almeida-Filho, N., Barreto, M. L. (2005). Ambiente familiar e desenvolvimento cognitivo infantil: Uma abordagem epidemiológica. Revista de Saúde pública, 39, 606-611.

Barker, G., \& Rizzini, I. (2002). Repensando o desenvolvimento infantil no contexto da pobreza no Brasil. $O$ Social em Questão, 7, 7-22.

Barros, R. P.; Carvalho, M., \& Franco, S. (2006). Pobreza multidimensional no Brasil. Rio de Janeiro: IPEA. pp.7-37

Psicol. Argum. 2014 jan./mar., 32(76), 79-92 
Bear, M. F., Connors, B. W., \& Paradiso, M. A. (2008). Neurociências desvendando o sistema nervoso. 3a ed. Porto Alegre: Artmed.

Beckett, C., Maughan, B., Rutter, M., Castle, J., Colvert, E., Groothues, C., Kreppner, J., Stevens, S., O'Connor, T. G., \& Sonuga-Barke, E. J. S. (2006). Do the effects of early severe deprivation on cognition persist into early adolescence? From the English and Romanian Adoptees Study. Child Development, 77, 696-711.

Belsky (1995). Expanding the ecology of human development: an evolutionary perspective. In P. Moen, G. H. Elder Jr., \& K. Lüscher. Examining lives in context: perspectives on the ecology of human development. American Psychological Association. pp. 542-561.

Bernal, E. M. B. (2004). Arquivos do abandono: experiências de crianças e adolescentes internados em instituições de Serviço Social de Menores de São Paulo (19381960). São Paulo: Cortez.

Brancalhone, P. G., Fogo, J. C., \& Williams, L. C. A. (2004). Crianças Expostas à Violência Conjugal: avaliação do desempenho acadêmico. Psicologia: Teoria $e$ Pesquisa, 20, 113-117.

Brazelton, T. B., \& Greenspan, S. I. (2002). As necessidades essenciais das crianças. 0 que toda criança precisa para crescer, aprender e se desenvolver. (C. Monteiro, Trad.). Porto Alegre: Artmed. (Obra original publicada em 2000).

Bronfenbrenner, U. (1996). A ecologia do desenvolvimento humano: experimentos naturais e planejados. (M. A. Veronese, Trad.). Porto Alegre: Artmed (Obra original publicada em 1994).

Calamante, A. J. (2007). Saneamiento básico, agua potable y salud pública. In J. A. Colombo (Org). Pobreza e desenvolvimento infantil: uma contribuição multidisciplinar. Buenos Aires: EDUFPA. pp. 327-353.

Carvalho, A. M. (2002). Crianças institucionalizadas e desenvolvimento: possibilidades e desafios. In E. da R. Lordelo, A. M. Carvalho, \& S. H. Koller (Orgs.). Infância brasileira e contextos de desenvolvimento. (pp. 19-44). São Paulo/Salvador: Casa do Psicólogo/ Universidade Federal da Bahia.
Cavalcante, L. I. C. (2008). Ecologia do cuidado: interações entre a criança, o ambiente, os adultos e seus pares em instituição de Abrigo. Tese de doutorado, Programa de Pós-Graduação em Teoria e Pesquisa do Comportamento, Universidade Federal do Pará, Belém, Pará, Brasil.

Cavalcante, L. I. C.; Magalhães, C. M. C., \& Costa, L. N. (2012). Caretaking behavior among siblings in children's shelters. Psicologia: Reflexão e Crítica, 25, 165-173.

Colombo, J. A. (2007). Acerca Del desarrollo cerebral infantil: entre el daño y la optimización social. In J. A. Colombo (Org). Pobreza e desenvolvimento infantil: uma contribuição multidisciplinar. Buenos Aires: Paidós. pp. 97-114.

Díaz, A. (2007). Estado nutricional y desarrollo de la infancia en situación de pobreza. In J. A. Colombo (Org). Pobreza e desenvolvimento infantil: uma contribuição multidisciplinar. Buenos Aires: Paidós. pp. 141-160.

Dimenstein, R., Simplício, J. L., Ribeiro, K. D. S., \& Melo, I. L. P. (2003). Influência de variáveis socioeconômicas e de saúde materno-infantil sobre os níveis de retinol no colostro humano. Jornal de Pediatria, 79, 513-518.

Ferreira, M. C. T., \& Marturano, E. M. (2002). Ambiente familiar e os problemas de comportamento apresentados por crianças com baixo desempenho escolar. Psicologia: Reflexão e Crítica, 15(1), 35-44.

Fisberg, R. M., Marchioni, D. M. L., \& Cardoso, M. R. A. (2004) Estado nutricional e fatores associados ao déficit de crescimento de crianças frequentadoras de creches públicas do município de São Paulo, Brasil. Caderno de Saúde Pública, 20, 812-817.

Fundo das Nações Unidas para a Infância (2004). Ser criança na Amazônia: uma análise das condições de desenvolvimento infantil na região norte do país. Belém: Autor.

Fundo das Nações Unidas para a Infância (2005). Situação da infância brasileira: crianças de 0 a 6 anos. $O$ direito à sobrevivência e ao desenvolvimento. Brasília: Autor. 
Gallo, A. E., \& Williams, L. C. A. (2005). Adolescentes em conflito com a lei: uma revisão dos fatores de risco para a conduta infracional. Psicologia: Teoria $e$ Prática, 7, 81-95

Habigzang, L. F., Koller, S. H., Azevedo, G. A., \& Machado, P. X. (2005). Abuso sexual infantil e dinâmica familiar: aspectos observados em processos jurídicos. Psicologia: Teoria e Pesquisa, 21(3), 341-348. Recuperado em 12 mar. 2006, de http://www.scielo.br/scielo.php?script=sci_ arttext\&pid $=$ S0102-37722005000300011\&lng =e $n \& n r m=i s o$

Halpern, R. \& Figueiras, A. C. M. (2004). Influências ambientais na saúde mental da criança. Jornal de Pediatria, 80, 104-110.

Horta, Bernardo L., Barros, Fernando C., Halpern, Ricardo, \& Victora, Cesar G.. (1996). Baixo peso ao nascer em duas coortes de base populacional no Sul do Brasil. Cadernos de Saúde Pública, 12(Suppl. 1), S27-S31. Recuperado em 17 out. 2014, de http://www.scielo.br/scielo.php?script=sci_arttext\&pid=S0102$-311 X 1996000500005 \& \operatorname{lng}=$ en\&tlng=pt. 10.1590/ S0102-311X1996000500005.

Instituto Brasileiro de Geografia e Estatística (2004a). Censo Demográfico 2000. Recuperado em 12 mar. 2006 de http://www.ibge.gov.br/home/presidencia/noticias/20122002censo.shtm

Instituto Brasileiro de Geografia e Estatística (2004b). Estatísticas do Registro Civil 2004. Recuperado em 12 mar. 2006 de http://www.ibge.gov.br/home/ estatistica/populacao/registrocivil/2004

Instituto Brasileiro de Geografia e Estatística (2006a). Pesquisa Nacional por Amostra de Domicílios 2006. Recuperado em 10 out. 2007 de http:// www.ibge.gov.br/home/estatistica/populacao/ trabalhoerendimento/pnad2006.

Instituto Brasileiro de Geografia e Estatística (2006b). Perfil dos municípios brasileiros - 2006. Recuperado em 3 dez. 2007 de http://www.ibge.gov.br/home/ estatistica/economia/perfilmunic/2006

Instituto de Pesquisa Econômica Aplicada (2004). Levantamento nacional de abrigos para crianças $e$ adolescentes da rede SAC. Brasília. Recuperado em 2 jul. 2005 de http://www.mpsp.mp.br/portal/page/ portal/infanciahome_c/acolhimento_institucional/ Doutrina_abrigos/IPEA._Levantamento_Nacional_ de_abrigos_para_Criancas_e_Adolescentes_da_Rede_ SAC.pdf

Kappel, D. B. (2007). Índice de desenvolvimento infantil no Brasil: uma análise regional. Revista Brasileira de Educação, 12, 232-240.

Lewandowski, D. C., De Antoni, C., Koller, S. H., \& Piccinini, C. A. (2002). Paternidade na adolescência e os fatores de risco e de proteção para a violência na interação pai-criança. Interações, 13(7), pp. 11-100.

Morais, N. A., Leitão, H. S., Koller, S. H., \& Campos, H. R. (2004). Notas sobre a experiência de vida num internato: aspectos positivos e negativos para o desenvolvimento dos internos. Psicologia em Estudo, 3, 379-387.

O’Donnell, A. M., \& Porto, A. (2007). Las carencias alimentarias en el país. Su impacto sobre el desarrollo infantil. In J. A. Colombo (Org). Pobreza e desenvolvimento infantil: uma contribuição multidisciplinar. Buenos Aires: Paidós. pp. 141-160.

Paiva, G. S., Lima, A. C. V. M. S., Lima, M. C., \& Eickmann, S. H. (2010). The effect of poverty on developmental screening scores among infants. São Paulo Medicinal Journal, 128, 276-283.

Petetta, D. R. (2007). Evolución epidemiológica de la pobreza urbana na Argentina: el impacto sobre indicadores demográficos, educativos y laborales. In J. A. Colombo (Org). Pobreza e desenvolvimento infantil: uma contribuição multidisciplinar. Buenos Aires: EDUFPA. pp. 327-353.

Poletto, M., Wagner, T. M. C., \& Koller, S. H. (2004). Resiliência e desenvolvimento infantil de crianças que cuidam de crianças: uma visão em perspectiva. Em Psicologia: Teoria e Pesquisa, 20, 241-250.

Rede Nacional Primeira Infância (2010). Plano Nacional pela Primeira Infância. Brasília, DF: Autores.

Roy, P., \& Rutter, M. (2006). Institutional care: associations between inattention and early

Psicol. Argum. 2014 jan./mar., 32(76), 79-92 
reading performance. Journal of Child Psychology and Psychiatry, 41, 480-487.

Roy, P., Rutter, M., \& Pickles, A. (2000). Institutional care: risk from family background or pattern of rearing? Journal of Child Psychology and Psychiatry, 41, 139-149.

Santos-Monteiro, J., Guedes, R. C. A., Castro, R. M., Cabral Filho, J. E. (2002). Estimulação psicossocial e plasticidade cerebral em desnutridos. Revista Brasileira Saúde Materno Infantil, 2(1), 15-22.

Serrano, S. A. (2008). 0 abrigamento de crianças de zero a seis anos de idade em Ribeirão Preto: caracterizando esse contexto. Tese de doutorado, Faculdade de Filosofia, Ciências e Letras de Ribeirão Preto, Ribeirão Preto, São Paulo, Brasil.

Sigal, J., Perry, J. C., Rossignol, M. I., \& Ouimet, M. C. (2003). Unwanted infants: psychological and physical consequences of inadequate orphanage care 50 years later. American Journal of Orthopsychiatry, 73, 3-12.
Silva, N. C. B., Nunes, C. C., Betti, M. C. M., \& Rios, K. S. A. (2008). Variáveis da família e seu impacto sobre o desenvolvimento infantil. Temas em Psicologia, 16, 513-518.

Siqueira, A. C., \& Dell'Aglio, D. D. (2006). 0 impacto da institucionalização na infância e na adolescência: uma revisão da literatura. Psicologia e Sociedade, 18, 71-80.

Vegas, E., \& Santibáñez, L. (2010). La promesa del desarrollo en la primera infância en América Latina y el Caribe. Washington, DC/Bogotá, Colômbia: Banco Mundial en coedición con Mayol Ediciones S.A.

Weber, L. N. D., \& Kossobudzki, L. H. M. (1996). Filhos da solidão: institucionalização, abandono e adoção. Curitiba: Governo do Estado do Paraná.

Wolff, P. H., \& Fesseha, G. (1999). The orphans of Eritrea: a five-year follow-up study. Journal Child Psychology and Psychiatry, 40, 1231-1237. 